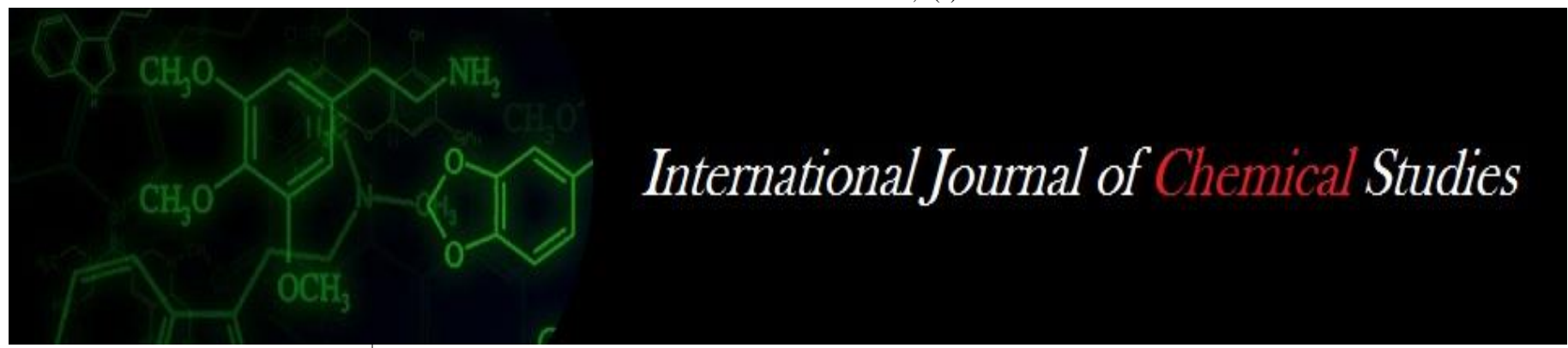

P-ISSN: 2349-8528

E-ISSN: 2321-4902

IJCS 2020; 8(1): 2185-2188

(C) 2020 IJCS

Received: 10-11-2019

Accepted: 12-12-2019

Kumawat S

Research Scholar, Department of Plant Breeding and Genetics,

SKN Agriculture University,

Jobner, Rajasthan, India

\section{Jakhar ML}

Professor, Department of Plant

Breeding and Genetics, SKN

Agriculture University, Jobner,

Rajasthan, India

\section{Shekhawat K}

Research Scholar, Department of Plant Breeding and Genetics,

SKN Agriculture University,

Jobner, Rajasthan, India

\section{Kumar R}

Research Scholar, Department of

Plant Breeding and Genetics,

SKN Agriculture University,

Jobner, Rajasthan, India

\section{Choudhary $\mathbf{R}$}

Research Scholar, Department of Plant Breeding and Genetics,

SKN Agriculture University,

Jobner, Rajasthan, India

Get S

Research Scholar, Department of Plant Breeding and Genetics,

SKN Agriculture University,

Jobner, Rajasthan, India

Jat H

Research Scholar, Department of Plant Breeding and Genetics, SKN Agriculture University, Jobner, Rajasthan, India

Corresponding Author: Kumawat S

Research Scholar, Department of Plant Breeding and Genetics, SKN Agriculture University, Jobner, Rajasthan, India

\section{Effect of photoperiod In vitro callus induction and regeneration of Guggul [Commiphora wightii (Arnott)]}

\author{
Kumawat S, Jakhar ML, Shekhawat K, Kumar R, Choudhary R, Get S \\ and Jat $\mathrm{H}$
}

DOI: https://doi.org/10.22271/chemi.2020.v8.i1ag.8591

\begin{abstract}
The impact of various photoperiod regimes on callus induction from callus culture in guggul leaf explants was carried out in present investigation. The leaf explants showing the maximum callus $(0.90 \mathrm{~g})$ induction on MS medium supplemented with $2.0 \mathrm{mg} / \mathrm{l}$ 2,4-D with 100 per cent frequency were tested for their response to different regimes $(10: 14,12: 12,14: 10,16: 8)$ of photoperiod. The cultures were incubated with a light intensity of 3000 lux at $25 \pm 2{ }^{\circ} \mathrm{C}$. Maximum callus induction was observed $(0.95$ g)in leaf explants incubated at 14:10 hours photoperiod with 100 per cent frequency followed by $(0.88 \mathrm{~g})$ with 100 per cent frequency at 10:14 hours photoperiod. Minimum callus induction $(0.69 \mathrm{~g})$ was observed with 90 per cent at 12: 12 hours photoperiod regimes. Callus induction in leaf explant completely inhibited at 16:8 hours photoperiod. 14:10 was most suitable photoperiod regime for callus induction in leaf explants. Leaf derived callus $(2.0 \mathrm{mg} / 12$, 4-D, $5.0 \mathrm{mg} / \mathrm{l} \mathrm{Kn}+0.5 \mathrm{mg} / \mathrm{l} \mathrm{NAA}$ and $1.0 \mathrm{mg} / \mathrm{l} \mathrm{Kn})$ was subcultured at the same level of plant growth regulator to maintain the stock cultures. Shoot/ embryo morphogenesis was not observed on any of the these plant growth regulators except $2.0 \mathrm{mg} / \mathrm{l}$ 2, 4-D. Semi compact, light green callus proliferating from cut surface of the leaf explants on the medium supplemented with 2, 4-D $(2.0 \mathrm{mg} / \mathrm{l})$ when assessed for its organogenetic capacity. Upon subculture on cytokinin (BAP 0.1-3.0 mg/l) and auxin (2, 4-D 0.1-3.0 mg/l) added singly in the medium and in combination de novo shoot morphogenesis was observed. The reproducibility of this morphogenesis was only 25-30 per cent.
\end{abstract}

Keywords: Leaf, callus, in vitro, phenolic, browning, establishment, Guggul

\section{Introduction}

Indian traditional medicine method, guggul has been used as medicine for many thousands of years. Guggul is an important medicinal source and plays a key role in health in almost every region of the world, from ancient times to the present (Kala et al., 2007) ${ }^{[13]}$. Commiphora wightii (Arnott) is an important flowering plant belonging to the Burseraceae family with the number $2 n=26$ chromosome (Sobti and Singh, 1961) ${ }^{[22]}$. The name Commiphora originated from the Greek words kommi (meaning 'gum') and phero (meaning 'to bear'). In Indian languages, it is known by various names like guggul in Hindi, gukkulu and maishakshi in Tamil, guggulu in Sanskrit and Indian bdellium in English. The genus Commiphora is widely distributed in tropical regions of Africa, Madagascar, Asia, Australia and the Pacific islands (Good, 1974) ${ }^{[5]}$. Guggul grow well with mean annual rainfall of 225-500 $\mathrm{mm}$ and temperature ranging from $20-35^{\circ} \mathrm{C}$. It prefers loams to sandy loam soils with basic $\mathrm{pH}$ ranging from 7.5 to 9.0. In India, it is found in arid, rocky tracts of Rajasthan and Gujarat, Maharashtra and Karnataka (Kumar and Shankar, 1982) ${ }^{[14]}$. In Rajasthan it is found in the districts namely Jaisalmer, Barmer, Jodhpur, Jalore, Sirohi, Ajmer, Sikar, Churu, Jhunjhunu, Pali, Udaipur, Alwar (Sariska Tiger Reserve), Jaipur (Ramgarh, Jhalana area), Bhilwara and Rajsamand. Commiphora wightii is a tiny or shruby tree. It is a plant that grows slowly and takes 8 to 10 years to reach a height of 3 to 3.5 metres. The plant is dimorphic, one of which has bisexual and male flowers and the other of which have staminodic female flowers A third category of plant was also reported with only male flowers (Gupta et al., 1996) ${ }^{[6]}$. The fruits are like drupe, green berry. Fruit size varies between 6 and $8 \mathrm{~mm}$ in diameter and $5 \mathrm{~mm}$ in diameter. 
Sections of fruit that are exposed to the sun produce pinkish tinge. Seeds exhibit polyembryonic character. (Soni, 1998) [23].

Guggul produces a fragrant gum resin called gugal, guggul, or gugul which is used in the practice of Ayurvedic medicine in the incense and traditional remedy. Guggul gum is a mixture of $61 \%$ resin, $29.3 \%$ gum, $6.1 \%$ water, $0.6 \%$ volatile oil and $3.2 \%$ foreign matter (Jain and Nadgauda, 2013) ${ }^{[11]}$.

In 1966, an Indian Medical Researcher, G. V. Satyavati, first introduced Guggul to the scientific world (Deng, 2007) ${ }^{[4]}$. Guggul is considered to be endangered in India and is classified as ' Data Deficient ' in the IUCN Red Data List (IUCN, 2010) ${ }^{[8]}$ due to a lack of information on its conservation status as well as excessive and unscientific taping methods to increase yield of oleo-gum resin causes plant mortality leading to the species ' extinction. The wild population of this species has declined by more than 80 per cent over the past 84 years (three generation lengths) as a result of habitat loss and degradation, coupled with unregulated harvesting and tapping of oleo-gum resin. Some species produce a fragrant oleo-gum-resin after bark damage (Steyn, 2003) ${ }^{[24]}$. Therefore this species is listed as being critically endangered (IUCN, 2015) ${ }^{[9]}$. Over-exploitation, limited occurrence, broad habitat area, extreme population disturbance, very low regeneration and invasion of alien species means Commiphora wightii faces a high risk of extinction (Reddy et al., 2012 and Ved et al., 2015) ${ }^{[19,25] .}$

Natural regeneration and cultivation are nearly negligible compared to its degradation. Slow growing nature associated with poor seed germination is also the primary cause of endangerment for Commiphora wightii. Efforts are needed to conserve this species in nature and to propagate it extensively. The method of in vitro propagation may be used for the clonal propagation of selected germplasm, genetic improvement, active compound production in cell culture. Thus, the in vitro propagation method would be the promising choice for Commiphora wightii multiplication and conservation. Thus the present investigation has been undertaken to establish reliable protocol for study the effect of different photoperiod regimes on callus induction and shoot regeneration from callus culture in leaf explants of guggul. Thus the present investigation was undertaken to establish a reliable protocol for studying the effect of different photoperiod regimes on induction of callus induction and shoot regeneration from callus culture in guggul leaf explants.

\section{Material and Methods}

The latest investigation was conducted at Plant Breeding and Genetics Department, Jobner, S. K. N. College of Agriculture. Leaves were used as explants and collected from herbal garden held under the Department of Plant Breeding and Genetics, S.K.N. Agricultural College, Jobner. All chemicals that were used in this analysis were of analytical quality. The medium Murashige and Skoog (1962) [17] was used throughout the investigation. The culture media contained in glass containers sealed with cotton plugs and covered with aluminum foils were autoclaved at $15 \mathrm{psi}$ and $121{ }^{\circ} \mathrm{C}$ for 15 40 minutes. Exposure time depends on the volume of the liquid to be sterilized. After autoclaving the media were stored in dark for 48 hours at $25 \pm 2{ }^{\circ} \mathrm{C}$. Leaf Explants of guggul were washed thoroughly in running tap water for 20 minutes. These were again washed with liquid detergent (Rankleen) for 10 minutes with vigorous shaking. After washing with detergent, explants were again washed with running tap water to remove any trace of detergent for 5 minutes. Explants were surface sterilized with 0.1 per cent $\mathrm{HgCl}_{2}$ in a laminar air flow cabinet. leaves explants were sterilization for 1 minute. These were thoroughly washed four to five times with sterilized double distilled water and inoculated on the different culture media supplemented with callus induction at most responsive level of plant growth regulators. After sterilization the explants were inoculated on different culture media aseptically. For inoculation, explants were transferred to large sterile glass Petriplates with the help of sterile forceps under strict aseptic conditions. All cultures were incubated at $25 \pm 2{ }^{\circ} \mathrm{C}$ with light intensity of $3000-3500$ lux.

\section{Results and Discussion}

The leaf explants showing the maximum callus $(0.90 \mathrm{~g})$ induction on MS medium supplemented with $2.0 \mathrm{mg} / \mathrm{l}$ 2, 4-D with 100 per cent frequency were tested for their response to different regimes of photoperiod. Maximum callus induction was observed $(0.95 \mathrm{~g})$ in leaf explants incubated at 14:10 hours photoperiod with 100 per cent frequency (Fig.1) followed by $(0.88 \mathrm{~g})$ at 10:14 hours photoperiod with 100 per cent frequency. Minimum callus induction $(0.69 \mathrm{~g})$ was observed at 12:12 hours photoperiod regimes with 90 per cent. Callus induction in leaf explant completely inhibited at 16:8 hours photoperiod Table (1).

The ability to co-ordinate certain developmental processes to particular times of the year when environmental conditions are likely to be more favorable, confer distinct advantages. Time bound reproduction to spring season time so that vulnerable young offspring have the maximum possible time to develop before experiencing the harsh conditions of winter, for example, would result in a greater survival rate of the offspring. There is thus a selective advantage for plants and animals that have acquired mechanisms enabling them to sense seasonal differences through the detection and response to changes in photoperiod. The photoperiod is the amount of light and darkness in a daily cycle of $24 \mathrm{~h}$. Photoperiod controls many developmental responses in animals, plants and even fungi. The response to photoperiod has evolved because day length is a reliable indicator of the time of year, enabling developmental events to be scheduled to coincide with particular environmental conditions (Jackson, 2009) ${ }^{[10]}$.

Photoperiodism is the physiological reaction of organisms to the length of day or night. Photoperiodism can also be defined as the developmental responses of plants to the relative lengths of the light and dark periods. Hence, it should be emphasized that photoperiodic effects relate directly to the timing of both the light and dark periods.

In the present investigation different photoperiod regimes $(16: 8,14: 10,12: 12$ and 8:16) were assessed for callus induction in MS medium supplemented with responsive levels of plant growth regulator (2.0 mg/1 2, 4-D). Maximum callus proliferation was observed at 14:10 hour's photoperiod followed by 12:12 hour's. Similar results were also observed by Jakhar et al., $2012^{[12]}$, Kumawat, $2013^{[16]}$ in Aloe vera, Nagar, $2017^{[18]}$, Burdak et al., $2017^{[2]}$ in fenugreek and Kumar (2018) ${ }^{[14]}$ in pomegranate. Shortest dark hour's (16:8) were insufficient to proliferation of callus in leaf even at responsive level These finding were also in close to the findings of the Choudhary et al., 2017 and Aparna et al., 2017 $[1,3]$ in Gliricidia. 
Table 1: Effect of different photoperiod regimes on callus induction in leaf explant supplemented with $2.0 \mathrm{mg} / 1$ 2, 4-D

\begin{tabular}{|c|c|c|c|c|}
\hline S. No. & Photoperiod regime & Days taken in callus induction & Callus weight (mg) & Morphogenetic response (\%) \\
\hline 1 & $10: 14$ & 26.3 & 695 & 90 \\
\hline 2 & $12: 12$ & 24.1 & 880 & 100 \\
\hline 3 & $14: 10$ & 20.1 & 954 & 100 \\
\hline 4 & $16: 8$ & - & - & - \\
\hline
\end{tabular}

$(-)=$ No response

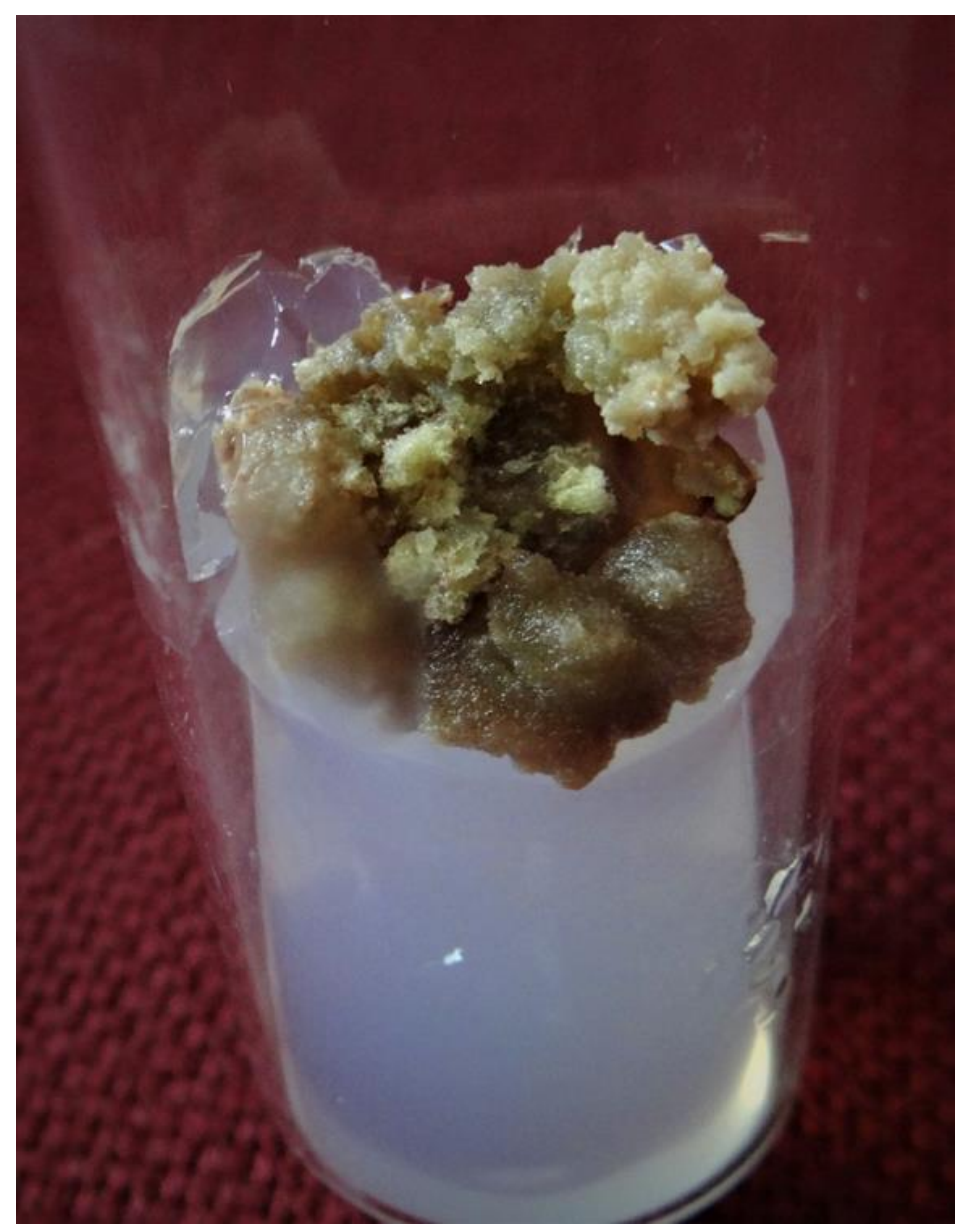

Fig 1: Callus induction in leaf explant at 14:10 photoperiod regimes on supplemented with $2.0 \mathrm{mg} / 1$ 2, 4-D

To establish stock callus cultures, nodal segment and leaf explants were obtained from healthy plant of guggul. These explants were incubated on MS medium supplemented with various cytokinins (BAP/Kn 0.5-5.0 mg/l) and auxin (NAA/2,
4-D 0.5-5.0 mg/l) added singly and in combination (Table 4.1, $4.2,4.3,4.4,4.5$ and 4.6). The following three levels were found best for callus induction in leaf and nodal segment explant.

The following three levels were found best for callus induction in leaf and nodal segment explant.

\begin{tabular}{|c|c|c|c|c|c|c|c|}
\hline \multicolumn{4}{|c|}{ Leaf explants } & \multicolumn{4}{c|}{ Nodal segment explant } \\
\hline Rank & Level of PGR & Texture of callus & colour & Rank & Level of PGR & Texture of callus & Colour \\
\hline I & $2.0 \mathrm{mg} / \mathrm{l} 2,4-\mathrm{D}$ & Semi-compact & Light green & I & $5.0 \mathrm{mg} / \mathrm{l} \mathrm{BAP}+5.0 \mathrm{mg} / \mathrm{l} \mathrm{NAA}$ & Compact & Light brown \\
\hline II & $5.0 \mathrm{mg} / \mathrm{Kn}+0.5 \mathrm{mg} / \mathrm{l} \mathrm{NAA}$ & Friable & Light green & II & $2.0 \mathrm{mg} / \mathrm{l} \mathrm{NAA}$ & Compact & Light brown \\
\hline III & $1.0 \mathrm{mg} / \mathrm{l} \mathrm{Kn}$ & Semi-compact & Light yellow & III & $0.5 \mathrm{mg} / \mathrm{l} \mathrm{BAP}+5.0 \mathrm{Mg} / \mathrm{l} \mathrm{NAA}$ & Compact & Light brown \\
\hline
\end{tabular}

Light green/ yellow friable and semi compact calli proliferated on cut surface of face leaf explants on MS medium supplemented with $2.0 \mathrm{mg} / \mathrm{l} 2,4-\mathrm{D} / 5.0 \mathrm{mg} / \mathrm{l} \mathrm{kn}+0.5$ $\mathrm{mg} / \mathrm{l} \mathrm{NAA} \mathrm{/} 1.0 \mathrm{mg} / \mathrm{l} \mathrm{Kn}$ were maintained through serial subcultures at an interval of 30-40 days to establish the stock callus

Leaf derived callus $(2.0 \mathrm{mg} / \mathrm{l}$ 2, 4-D, $5.0 \mathrm{mg} / \mathrm{l} \mathrm{Kn}+0.5 \mathrm{mg} / \mathrm{l}$ NAA and $1.0 \mathrm{mg} / \mathrm{K} \mathrm{K}$ ) was subcultured at the same level of plant growth regulator to maintain the stock cultures. Then this callus was subcultured on cytokinin (BAP 0.1-3.0 mg/l) and auxin (2, 4-D, 0.1-3.0 mg/l) added singly and in combination. Shoot/ embryo morphogenesis was not observed on any of the these plant growth regulators except $2.0 \mathrm{mg} / \mathrm{l} 2$, 4-D. Callus only proliferated further, getting a compact nature when ratio of cytokinin to auxin was high and remained parenchymatous on high auxin to cytokinin ratio. Semi compact, light green callus proliferating from cut surface of the leaf explants on the medium supplemented with 2, 4-D $(2.0 \mathrm{mg} / \mathrm{l})$ when assessed for its organogenetic capacity. Upon subculture on cytokinin (BAP 0.1-3.0 mg/l) and auxin (2, 4-D 0.1-3.0 $\mathrm{mg} / \mathrm{l}$ ) added singly in the medium and in combination de novo shoot morphogenesis was observed (Fig. 2). The reproducibility of this morphogenesis was only 25-30 per cent. 
In current investigation, regeneration from callus cultures could not be established truely at various levels of plant growth regulators added singly or in combination. Calli started turning brown without further growth. The browing of the calli could be due to the production of certain oxidatory products or phenols from the cells, which retard the growth of callus (Singh et al., 2010) ${ }^{[21]}$. There could be many reasons for this. Since only one genotype was tested for their morphogenetic potential, it appears that Commiphora wightii may be inherently less regenerative or recalcitrat. Halperin (1986) ${ }^{[7]}$ has pointed out that this block may be (i) genetic involving lack of totipotency or (ii) epigenetic - involving stable but potentially reversible constraints on the functioning of genes required for differentiation or (iii) physiological that cells are both totipotent genetically and without epigenetic constraints yet the proper culture environment is lacking to provide proper signal (e.g., lack of particular hormones, particular ratios or concentration or interference with singly by inhibitors present in the medium or released by explants).

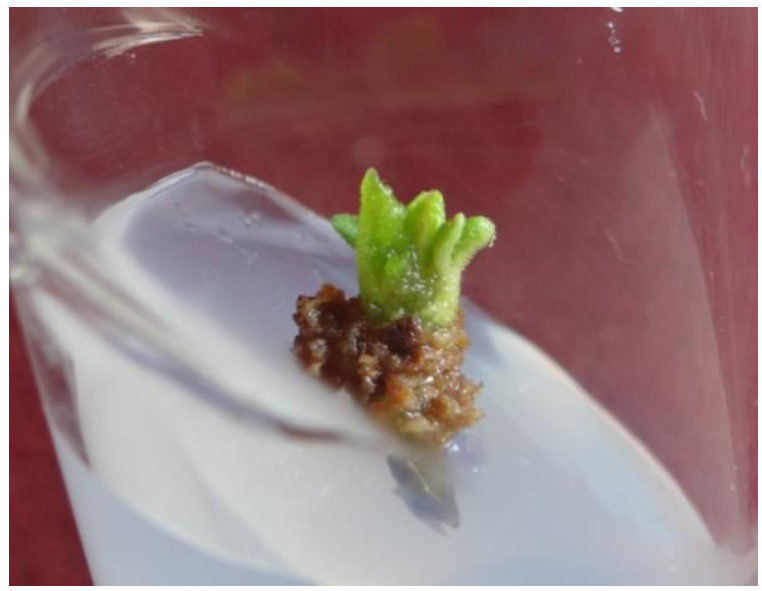

Fig 2: De novo shoot regeneration from leaf derived callus on 2.0 $\mathrm{mg} / \mathrm{l}$ 2, 4-D

\section{References}

1. Aparna, Jakhar ML, Choudhary K. Standardization of micropropagation in glyricidia [Gliricidia sepium (Jacq.) Steud.]. Journal of Plant Science Research. 2017; 33(1):11-15.

2. Burdak A, Jakhar ML, Nagar P, Kumar R, Bajya M. In vitro regeneration in fenugreek (Trigonella foenumgraecum L.). Research Journal of Chemical and Environment Sciences. 2017; 5(4):65-70.

3. Choudhary K, Jakhar ML, Aparna, Kumar R, Jat HR. In vitro regeneration in callus culture of gliricidia [Gliricidia sepium (Jacq.) Steud.]. International journal of Pure and Applied Bioscience. 2017; 5(5):40-47.

4. Deng R. Therapeutic effects of guggul and its constituent guggulsterone: Cardiovascular Benefits. Cardiovascular Therapeutics. 2007; 25(4):375-390.

5. Good R. The geography of the flowering plants. $4^{\text {th }}$ edition, London: Longman, 1974, 557p.

6. Gupta P, Shivanna KR, Ram MHY. Apomixis and polyembryony in guggul plant, Commiphora wightii. Annals of Botany. 1996; 78:67-72.

7. Helperin W. Morphogenesis in cell cultures. Annual Review of Plant Physiology. 1986; 30:395-417.

8. IUCN. IUCN Red list of threatened species, 2010.

9. IUCN. The IUCN Red list of threatened species, 2015.
10. Jackson SD. Plant responses to photoperiod. New Phytologist. 2009; 181:517-531.

11. Jain N, Nadgauda SR. Commiphora wightii (Arnott) Bhandari-A natural source of guggulsterone: Facing a high risk of extinction in its natural habitat. American Journal of Plant Sciences. 2013; 4(6):57-68.

12. Jakhar ML, Gurjar YR, Choudhar MR, Kakralya BL. Regeneration in callus cultures of Ghrithkumari (Aoe barbadensis Mill.) Journal of Plant Science Research. 2012; 28(1):131-136.

13. Kala CP, Sajwan BS. Revitalizing Indian systems of herbal medicine by the National Medicinal Plant Board through institutional network and capacity building, Current Science. 2007; 93(6):797-806.

14. Kumar R. Standardization of micropropagation protocol in pomegranate (Punica granatum L.) cv. Sindhuri. Ph. D. thesis, Sri Karan Narendra Agriculture University, Jobner, 2018.

15. Kumar S, Shankar V. Medicinal plants of the Indian deserts: Comiphora wightii (Arnott) Bhandari. Journal of Arid Enviroment. 1982; 5:1-11.

16. Kumawat N. In vitro regeneration in ghritkumari (Aloe barbadensis Mill.). M.Sc. Thesis, Swami Keswanand Rajasthan Agriculture University, Bikaner, 2013.

17. Murashige T, Skoog F. A revised medium for rapid growth and bioassays with tobacco tissue cultures. Physiologia Plantarum. 1962; 15:431-497.

18. Nagar P. In vitro culture of fenugreek (Trigonella foenum-graecum L.). M.Sc. Thesis, Sri Karan Narendra Agriculture University, Jobner, Rajasthan, 2017.

19. Reddy CS, Meena SL, Krishna PH, Charan PD, Sharma KC. Conservation threat assessment of Commiphora wightii (Arnott) Bhandari - An economically important species. Taiwania. 2012; 57(3):288-293.

20. Satyavati GV. Effect of an indigenous drug on disorders of lipid metabolism with special reference to atherosclerosis and obesity (medoroga), MD Thesis, (Banaras Hindu University, Varanasi, 1966.

21. Singh N, Garg A, Yadav K, Kumari S. Influence of growth regulators on the explants of Commiphora mukul (Hook. ex Stocks) England. under in vitro conditions. Researcher. 2010; 2(7):41-48.

22. Sobti SN, Singh SD. A chromosomal survey of medicinal plants. Indian Acadamic Science. 1961; 54(3):138-144.

23. Soni V. In situ conservation of Commiphora wightii a red listed medicinal plants species of Rajasthan State, India. Final project report SSC, IUCN, 2008.

24. Steyn M. The in vitro biological activity of selected Southern Africa Commiphora: United Litho South Africa, 2003, 34.

25. Ved D, Saha D, Ravikumar K, Haridasan K. Commiphora wightii, The IUCN Red list of threatened species, 2015. 